\title{
Capsaicin induces immunogenic cell death in human osteosarcoma cells
}

\author{
TAO JIN ${ }^{1}$, HONGYAN WU ${ }^{2}$, YANLIN WANG ${ }^{2}$ and $\mathrm{HAO} \mathrm{PENG}^{1}$ \\ ${ }^{1}$ Department of Orthopedics, Renmin Hospital of Wuhan University, Wuhan, Hubei 430060; \\ ${ }^{2}$ Laboratory of Tumor Microenvironment and Immunotherapy, Medical College of Three Gorges University, \\ Yichang, Hubei 443002, P.R. China
}

Received March 26, 2015; Accepted April 28, 2016

DOI: $10.3892 /$ etm.2016.3368

\begin{abstract}
Immunogenic cell death (ICD) is characterized by the early surface exposure of calreticulin (CRT). As a specific signaling molecule, CRT on the surface of apoptotic tumor cells mediates the recognition and phagocytosis of tumor cells by antigen presenting cells. To date, only a small quantity of anti-cancer chemicals have been found to induce ICD, therefore it is clinically important to identify novel chemicals that may induce ICD. The purpose of the present study is to explore the function of capsaicin in inducing ICD. In the current study, MTT assays were used to examine the growth inhibiting effects of MG-63 cells when they were treated with capsaicin or cisplatin. Mitochondrial membrane potential and western blot analysis were used to investigate capsaicin- and cisplatin-induced apoptosis. In addition, the effects of capsaicin and cisplatin were evaluated for their abilities in inducing calreticulin membrane translocation and mediating ICD in human osteosarcoma cells (MG-63). The results demonstrated that capsaicin and cisplatin can induce the apoptosis of MG-63 cells. However, only capsaicin induced a rapid translocation of CRT from the intracellular space to the cell surface. Treatment with capsaicin increased phagocytosis of MG-63 cells by dendritic cells (DCs), and these MG-63-loaded DCs could efficiently stimulate the secretion of IFN- $\gamma$ by lymphocytes. These results identify capsaicin as an anti-cancer agent capable of inducing ICD in human osteosarcoma cells in vitro.
\end{abstract}

\section{Introduction}

Osteosarcoma (OS) is the most common primary malignant bone tumor in children and adolescents (1). OS arises

Correspondence to: Professor Hao Peng, Department of Orthopedics, Renmin Hospital of Wuhan University, 99 Zhangzhidong Road, Wuhan, Hubei 430060, P.R. China E-mail: 2602858127@qq.com

Key words: capsaicin, immunogenic cell death, calreticulin, osteosarcoma, tumor specific immune response, dendritic cells, phagocytosis assays predominantly in the long bone metaphysis, particularly in the distal femur, proximal tibia and proximal humerus (2). Previously, the majority of patients with OS were treated by amputation; however, the 5-year survival rate was $<20 \%$, primarily due to lung metastases (3). With the introduction of chemotherapy into multi-modal treatment for OS, its prognosis has improved (2). In the past 20 years, although numerous international research groups have conducted a large quantity of research on OS, its survival rate remains unchanged (4-6).

The concept of immunogenic cell death (ICD) of tumor cells has emerged in recent years, which is a cell death modality that is able to stimulate an immune response against homologous tumor cells $(7,8)$. This concept was first proposed in the context of anticancer chemotherapy, and was based on animal experiments that indicated that tumor specific immune responses could determine the efficacy of anticancer therapies (9). ICD is characterized by the early surface exposure of calreticulin (CRT) (10).

To date, only a small number of conventional cytotoxic anticancer therapeutics are able to induce ICD (11); therefore it is of clinical significance to identify novel chemicals that can induce ICD. Capsaicin, a homovanillic acid derivative and the spicy component of chili pepper, has been shown to have cytotoxicity towards cancer cells and immunomodulatory functions, suggesting its potential application in tumor therapy (12). It has been reported that intratumoral administration of capsaicin elicits a $\mathrm{T}$ cell-mediated antitumor immune response, resulting in the regression of advanced preexisting solid tumors (12). In addition, research by D'Eliseo et al (13) indicates that capsaicin can stimulate anticancer immunity.

In the present study, the effects of capsaicin were evaluated for its abilities in inducing CRT membrane translocation and mediating ICD in a human MG-63 OS cell line. As it has been reported that cisplatin could not induce ICD in tumor cells, the present study used cisplatin as a control. The present results indicated that capsaicin induced a rapid membrane translocation of CRT. Furthermore, apoptotic MG-63 cells induced by capsaicin could be engulfed more efficiently by phagocytes and these phagocytes loaded with apoptotic MG-63 cells had the stronger ability in activating tumor-specific T-cells which could secrete IFN- $\gamma$. These data demonstrate that capsaicin can induce ICD in human OS cells. 


\section{Materials and methods}

Cell line. The human OS cell line MG-63 was purchased from the Cell Bank of China (Wuhan, China). The cells were maintained at $37^{\circ} \mathrm{C}$ in $5 \% \mathrm{CO}_{2}$ and Dulbecco's modified Eagle medium (DMEM), which contains 10\% heat-inactivated fetal bovine serum (Gibco; Thermo Fisher Scientific, Inc., Waltham, MA, USA), $100 \mu \mathrm{g} / \mathrm{ml}$ streptomycin and 100 units $/ \mathrm{ml}$ penicillin.

Materials. Capsaicin, DMEM, 3,3'-dihexyloxacarbocyanine iodide $\left(\mathrm{DiOC}_{6}\right)(3)$ and MTT were purchased from Sigma-Aldrich (St. Louis, MO, USA). Rabbit-anti-human CRT polyclonal antibody was purchased from Stressgen (Victoria, BC, Canada; cat. no. SPC-122B). Mouse anti-human phycoerythrin (PE)-conjugated CD11c monoclonal antibody was purchased from eBioscience (San Diego, CA, USA; cat. no. 12-0116-42). Rabbit anti-B-cell lymphoma 2 (Bcl-2) and rabbit anti-Bcl-2-associated $\mathrm{X}$ protein (Bax) monoclonal antibodies, and horseradish peroxidase (HRP)-conjugated anti-rabbit IgG, were purchased from Santa Cruz Biotechnology, Inc. (Dallas, TX, USA; cat. nos. sc-492, sc-6236 and sc-516087, respectively). PE-conjugated goat anti-rabbit IgG polyclonal antibody was obtained from R\&D Systems, Inc. (Minneapolis, MN, USA; cat. no. IC108P). Recombinant human interleukin (IL)-2, IL-4 and granulocyte-macrophage colony-stimulating factor (GM-CSF) were purchased from PeproTech (Rocky Hill, NJ, USA). Lymphocyte separation medium was purchased from Tianjin Haoyang Biological Manufacture, Co., Ltd. (Tianjin, China). IL-4 and IFN- $\gamma$ enzyme-linked immunosorbent assay (ELISA) kits were purchased from Wuhan Boster Biological Technology, Ltd. (Wuhan, China).

MTT assay. MG-63 cells were seeded onto 96-well tissue culture plates at a density of $2 \times 10^{3}$ cells $/ 100 \mu \mathrm{l}$ per well, and incubated for $24 \mathrm{~h}$ at $37^{\circ} \mathrm{C}$. The next day, the media were replaced with $100 \mu \mathrm{l}$ fresh complete medium containing capsaicin $(0,12.5,25,50,100,200$ and $400 \mu \mathrm{M})$ and cisplatin $(0,4,8,16,32,64$ and $128 \mu \mathrm{g} / \mathrm{ml})$. The cells treated with equal quantities of normal medium or solvent, instead of drugs, served as the control. After $24 \mathrm{~h}$ incubation, $100 \mu \mathrm{l}$ MTT solution $(0.5 \mathrm{mg} / \mathrm{ml})$ in DMEM without fetal bovine serum was added to each well and cultured for $4 \mathrm{~h}$ at $37^{\circ} \mathrm{C}$ in a humidified atmosphere. The medium was removed and $150 \mu \mathrm{l}$ DMSO was added into each well to dissolve the purple crystals, then the absorbance (A) at $570 \mathrm{~nm}$ was recorded. The cell proliferation inhibition rate was calculated according to the following formula: Cell proliferation inhibition rate $=\left(\mathrm{A}_{\text {control }}-\mathrm{A}_{\mathrm{drug}}\right) / \mathrm{A}_{\text {control }} \times 100 \%$.

Mitochondrial membrane potential (MMP). The lipophilic fluorescence dye $\mathrm{DiOC}_{6}$ (3) $(40 \mathrm{nM})$ was used to assay the mitochondrial membrane permeabilization. MG-63 cells $\left(2 \times 10^{6}\right)$ treated with $200 \mu \mathrm{M}$ capsaicin or $32 \mu \mathrm{g} / \mathrm{ml}$ cisplatin were stained with $\mathrm{DiOC}_{6}(3)$ for $15 \mathrm{~min}$ at $37^{\circ} \mathrm{C}$ and analyzed immediately by flow cytometry (FCM) equipped with a standard $15 \mathrm{~mW}$ argon-ion laser (488 nm) to excite $\mathrm{DiOC}_{6}(3)$. Then, a narrow band filter was used to collect emissions between 515 and $545 \mathrm{~nm}$. A minimum of 10,000 cells were analyzed by FCM for each data point.
Western blot analysis. MG-63 cells $\left(2 \times 10^{6}\right)$ were cultured in DMEM medium containing $200 \mu \mathrm{M}$ capsaicin or $32 \mu \mathrm{g} / \mathrm{ml}$ cisplatin for 12 or $24 \mathrm{~h}$ and harvested. Cells were then lysed with cell lysis buffer (Tris $50 \mathrm{mM}, \mathrm{NaCl} 150 \mathrm{mM}$, SDS $0.1 \%$, Sodium Deoxycholate $0.5 \%$ and $1 \%$ Triton X-100) for $20 \mathrm{~min}$ on ice. The protein concentrations were determined using the Pierce BCA Protein Assay kit (Thermo Fisher Scientific, Inc.), after which the proteins in the lysate $(45 \mu \mathrm{g})$ were separated by $10 \%$ SDS-PAGE and transferred onto a PVDF membranes. The membranes were blocked with fat-free milk solution $(5 \%, \mathrm{w} / \mathrm{v})$ for $12 \mathrm{~h}$ and then incubated with rabbit anti-Bcl-2 and anti-Bax monoclonal antibodies $(1: 1,000)$ or anti-CRT polyclonal antibody $(1: 1,000)$ at $4^{\circ} \mathrm{C}$ for $12 \mathrm{~h}$. After washing 3 times with TBST, the membrane was incubated with an HRP-conjugated anti-rabbit IgG antibody $(1: 4,000)$ at room temperature for $1 \mathrm{~h}$ and developed using electrochemiluminescence.

Detection of CRT on the cell surface by FCM. MG-63 cells were cultured in DMEM medium containing $200 \mu \mathrm{M}$ capsaicin or $32 \mu \mathrm{g} / \mathrm{ml}$ cisplatin for $12 \mathrm{~h}$ and harvested. After washing once with phosphate-buffered saline (PBS), the cells were incubated with rabbit anti-CRT polyclonal antibody $(1: 1,000)$ at room temperature for $1 \mathrm{~h}$, following by washing and incubation with PE-conjugated goat anti-rabbit IgG polyclonal antibody (1:500) at room temperature for $2 \mathrm{~h}$ (avoiding light). After washing with PBS, the cells were analyzed by FCM to identify CRT on the cell surface.

In vitro phagocytosis assays. Peripheral blood mononuclear cells (PBMCs) were isolated from human blood using lymphocyte separation medium (density, $1.077 \mathrm{~g} / \mathrm{ml}$ ) according to the manufacturer's instructions. Following the last wash, PBMCs $\left(5 \times 10^{6}\right)$ were resuspended in RPMI-1640 and plated in 6-well culture plates. After $3 \mathrm{~h}$ incubation, the monocytes were purified by removing the non-adherent cells in the supernatant. Purified monocytes were cultured in a medium supplemented with $30 \mathrm{ng} / \mathrm{ml}$ recombinant human GM-CSF and $10 \mathrm{ng} / \mathrm{ml}$ recombinant human IL-4 in 6-well plates $\left(1 \times 10^{6}\right.$ cells/well). After 7 days, the non-adherent and loosely adherent cells were harvested as the dendritic cells (DCs) and were used as the effector cells for the phagocytosis assay. The MG-63 cells $\left(1 \times 10^{6}\right)$ incubated with $200 \mu \mathrm{M}$ capsaicin or $32 \mu \mathrm{g} / \mathrm{ml}$ cisplatin for $12 \mathrm{~h}$ were labeled with the green dye carboxyfluorescein diacetate succinimidyl ester $(1 \mu \mathrm{M})$ for $10 \mathrm{~min}$ and were used as the target cells. The effector and target cells were co-cultured at $37^{\circ} \mathrm{C}$ for $2 \mathrm{~h}$ at a $1: 1$ effector/target ratio. After 3 washes, anti-human CD11c PE was added to the cell mixture for $30 \mathrm{~min}$ at room temperature (in the dark) to label the effector cells. The cells were washed with PBS and analyzed by FCM. The phagocytotic efficiency was represented by the cell ratio of the double-positive cell number over the total cell number.

IFN- $\gamma$ and IL-4 expression level analysis. PBMCs were isolated as described above. Following the last wash, PBMCs $\left(5 \times 10^{6}\right)$ were resuspended in RPMI-1640 and plated in 6-well culture plates. After $3 \mathrm{~h}$ incubation, the non-adherent cells were harvested as lymphocytes, and DCs were induced as described above. The DCs loaded with drug-treated MG-63 cells were co-cultured with lymphocytes at a ratio of 1:4. A volume of 
$200 \mathrm{U} / \mathrm{ml}$ IL-2 was added into the cell mixture during the culture period. After $24 \mathrm{~h}$, the supernatant was collected, and the IFN- $\gamma$ and IL-4 expression levels in the supernatant were measured by ELISA, according to the manufacturer's instructions.

Statistical analysis. Data are presented as the mean \pm standard deviation of three independent experiments. Student's $\mathrm{t}$-tests were performed for the comparison of results between different groups. All of the tests were performed using SPSS software, version 17.0 (SPSS, Inc., Chicago, IL, USA). P<0.05 was considered to indicate a statistically significant difference.

\section{Results}

Growth inhibition of MG-63 cells by capsaicin or cisplatin. An MTT assay was used to examine the growth inhibiting effects of capsaicin and cisplatin on MG-63 cells. The result showed that capsaicin and cisplatin significantly inhibit the growth of MG-63 cells in a dose-dependent manner (Fig. 1). After $24 \mathrm{~h}$ treatment, the inhibition percentage was $48.5 \%$ for $200 \mu \mathrm{M}$ capsaicin and $58.3 \%$ for $32 \mu \mathrm{g} / \mathrm{ml}$ cisplatin. Since these drug concentrations were close to median lethal doses (capsaicin, $165.7 \mu \mathrm{M}$; cisplatin, $16.76 \mu \mathrm{g} / \mathrm{ml}$ ), these concentrations were used to treat cells in the following experiments.

Alteration of MMP induced by capsaicin and cisplatin. Decreased MMP is a feature of apoptotic cells. In order to determine whether capsaicin and cisplatin can induce apoptosis of MG-63 cells, the effect of the drugs on the MMP was evaluated by FCM. The cells treated by $200 \mu \mathrm{M}$ capsaicin or $32 \mu \mathrm{g} / \mathrm{ml}$ cisplatin were stained with $\mathrm{DiOC}_{6}(3)$, and the MMP was detected by FCM. The results showed that treatment with both drugs could decrease the ratio of cells with green fluorescence (Fig. 2). This result suggests that capsaicin and cisplatin can induce the alteration of MMP in MG-63 cells, and then initiate endogenous apoptosis.

Effects of capsaicin and cisplatin on the expression of apoptosis-related proteins. To investigate the molecular mechanism underlying capsaicin- and cisplatin-induced apoptosis in human MG-63 OS cells, the expression levels of apoptosis-related proteins Bax and Bcl-2 were investigated using western blot analysis. As shown in Fig. 3, the expression level of Bax was markedly upregulated, and anti-apoptotic Bcl-2 was markedly downregulated, when the cells were treated with $200 \mu \mathrm{M}$ capsaicin or $32 \mu \mathrm{g} / \mathrm{ml}$ cisplatin for $24 \mathrm{~h}$. This suggests that Bcl-2 and Bax proteins are involved in capsaicin- and cisplatin-induced apoptosis.

Effect of capsaicin and cisplatin on the total expression levels of CRT in MG-63 cells. To validate whether capsaicin and cisplatin could affect CRT expression in MG-63 cells, a western blot assay was used to analyze CRT protein expression in whole cell lysates. The result showed that treating cells with capsaicin or cisplatin for $12 \mathrm{~h}$ did not change the total cellular CRT expression level (Fig. 4).

Capsaicin and cisplatin promoted the translocation of CRT onto the surface of $M G-63$ cells. To validate whether capsaicin
A

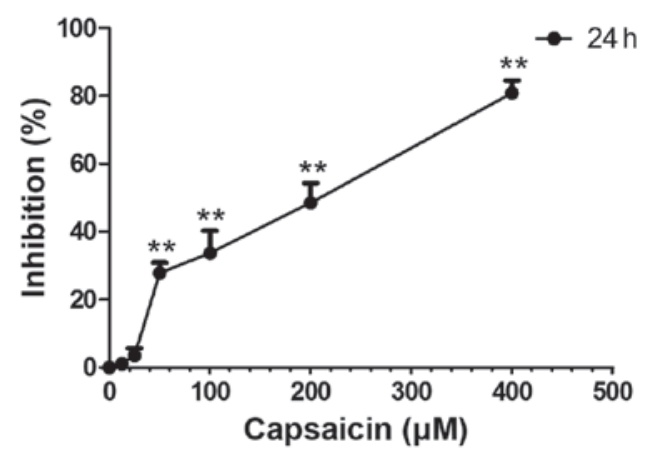

B

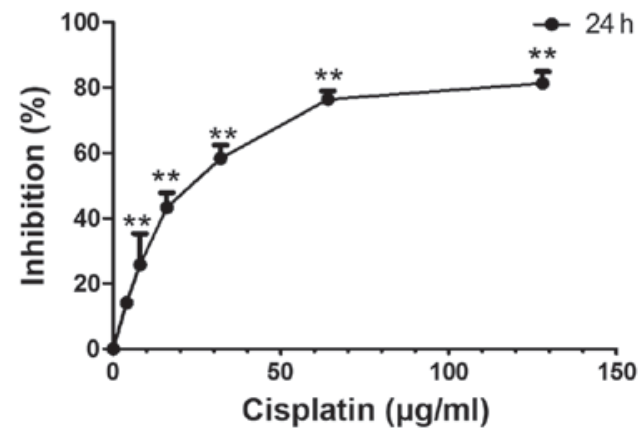

Figure 1. Growth inhibition of capsaicin and cisplatin on MG-63 cells at 24 h. (A) MG-63 cells treated with capsaicin. (B) MG-63 cells treated with cisplatin. $\mathrm{n}=4 .{ }^{* *} \mathrm{P}<0.01$ vs. control cells.

and cisplatin could affect CRT subcellular localization, MG-63 cells were treated with $200 \mu \mathrm{M}$ capsaicin or $32 \mu \mathrm{g} / \mathrm{ml}$ cisplatin, and FCM was used to assay CRT expression on the cell surface. The result (Fig. 5) showed that capsaicin treatment for $12 \mathrm{~h}$ significantly increased the expression of CRT on the cell surface, but no such effect was observed when the cells were treated with cisplatin. In this experiment, MG-63 cells have been dyed with fluorescence- labeled secondary antibody alone as a control, to exclude non-specific fluorescence binding to cells (Fig. 5).

Capsaicin treatment enhanced the phagocytosis of MG-63 cells by DCs in vitro. In view of the established role of CRT as an 'eat me' signal, and the results from the experiments described above, the difference of phagocytotic rates among the two drug-treated MG-63 cells by DCs was investigated. The DCs (effector cells) and drug-treated MG-63 cells (target cells) were co-cultured for $2 \mathrm{~h}$ in a 1:1 effector/target ratio, and the phagocytotic rate was determined by FCM. The results (Fig. 6) showed that MG-63 cells treated with capsaicin were phagocytosed at a higher rate than the MG-63 cells treated with cisplatin, indicating that CRT on the cell surface enhanced the phagocytosis of the human OS cells by DCs.

Activation of lymphocytes by DCs loaded with capsaicin-treated MG-63 cells in vitro. To investigate whether MG-63 cells with high CRT expression levels on the cell surface can induce antitumor immunity, the ability of DCs loaded with MG-63 cells to activate tumor cell-specific T-cell responses was investigated. The drug-treated MG-63 cells (target cells) were co-cultured with DCs (effector cells), then MG-63-loaded DCs were further co-cultured with 

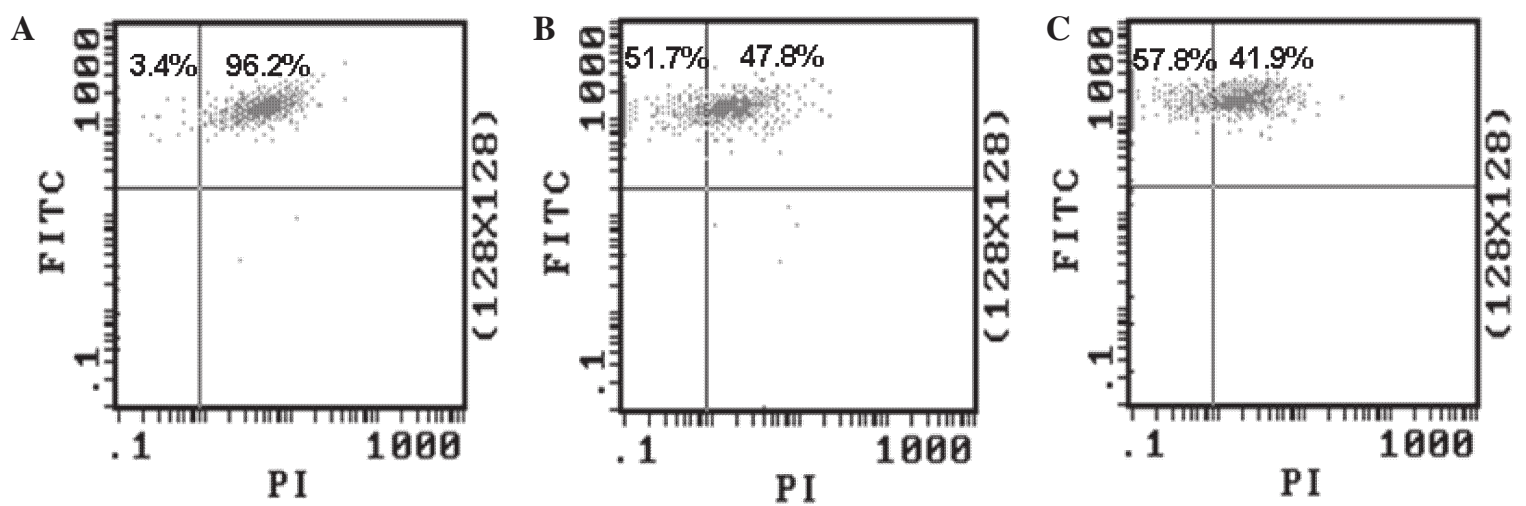

Figure 2. Capsaicin and cisplatin affect the mitochondrial membrane potential of MG-63 cells. (A) MG-63 cells; G-63 cells treated with (B) capsaicin and (C) cisplatin. FITC, fluorescein; PI, propidium iodide.

1

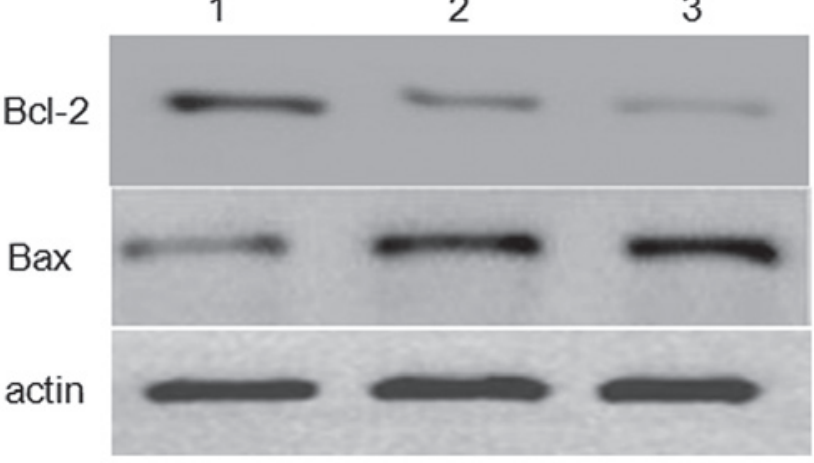

Figure 3. Western blot analysis was used to identify the expression of Bcl-2 and Bax in MG-63 cells. (1) MG-63 control cells; MG-63 cells treated with (2) cisplatin and (3) capsaicin. Bcl-2, B-cell lymphoma 2; Bax, Bcl-2-associated X protein.

lymphocytes for $24 \mathrm{~h}$. The IFN- $\gamma$ and IL-4 expression levels in the supernatant were then analyzed by ELISA. The result (Fig. 7) showed that, compared with MG-63 cells treated with cisplatin, capsaicin-treated MG-63 cells expressed a higher level of IFN- $\gamma(\mathrm{P}<0.01)$ in the supernatant, but no significant change was observed in the IL-4 expression level.

\section{Discussion}

The role of the immune system in anticancer therapy has been long neglected, as chemo- and radiotherapy-induced cell death frequently occurs through apoptosis, a cell death modality that was widely considered as immunologically silent, if not tolerogenic (14-16). In addition, cytotoxic chemotherapeutics are typically considered to be immunosuppressive $(17,18)$. Moreover, chemotherapy- induced nausea is often treated with high dose corticoids, which also induce an unwarranted immunosuppressive side effects (19).

In recent years, increasing evidence has demonstrated that a number of chemotherapeutics can induce ICD (20). Exploring effective ways and routes that can induce ICD have already become the hot spot of tumor prevention and therapy (21).

In the process of tumor cell apoptosis induced by various physical and chemical factors, CRT within endoplasmic reticulum (ER) is rapidly translocated to the cell surface (22). In homeostatic conditions, CRT is localized to the ER, where

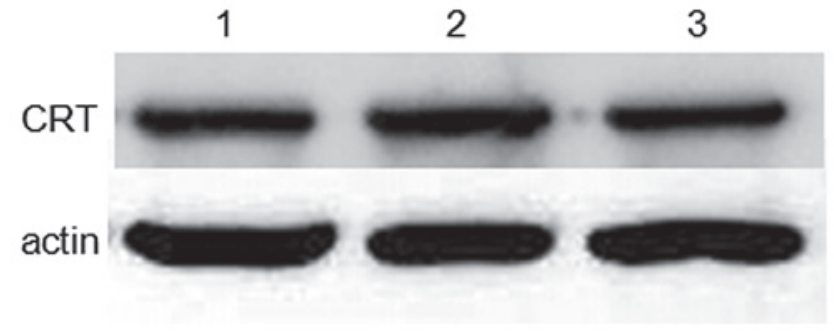

Figure 4. Western blot analysis was used to identify the expression of CRT in MG-63 cells. (1) MG-63 control cells; MG-63 cells treated with (2) cisplatin and (3) capsaicin. CRT, calreticulin.

it functions as a molecular chaperone and modulates calcium homeostasis (23). However, small quantities of CRT can be detected in other intracellular compartments, including the cytosol and nucleus $(24,25)$.

CRT on the cell surface has numerous functions, including the modulation of cell adhesion and migration (26), and mediating the phagocytosis of apoptotic tumor cells by professional and non-professional phagocytes (11,27-29). During the process of tumor cell apoptosis induced by special stimulus, CRT is rapidly translocated from the ER to the cell surface and serves as an 'eat me' signal that can be recognized by phagocytes within hours after the initiation of $\operatorname{ICD}(11,28,29)$. Subsequently, the tumor cells undergoing apoptosis downregulate the expression of 'do not eat me' signals, such as surface CD47, to facilitate the recognition and engulfment of the tumor cells by phagocytes, then to induce the anticancer immune response (30).

Only a small quantity of conventional cytotoxic anticancer therapeutics can induce ICD $(11,29)$; therefore it is clinically significant to explore novel chemicals that can induce ICD. In the current study capsaicin and cisplatin were tested for their ability to induce ICD. Human MG-63 OS cells were treated with capsaicin or cisplatin, and flow cytometry assay analysis was used to determine the changes in CRT expression levels on the cell surface. The result showed that capsaicin and cisplatin can induce apoptosis of MG-63 cells; however, only capsaicin treatment increased the expression level of CRT on the cell surface. Since the total CRT expression levels did not significantly change in MG-63 cells treated with capsaicin and cisplatin compared with the control, CRT appearing on the 
A

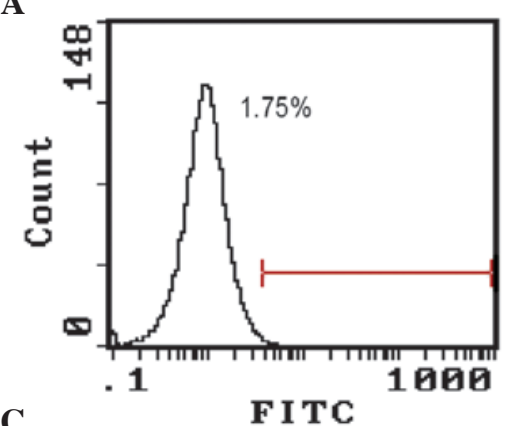

C

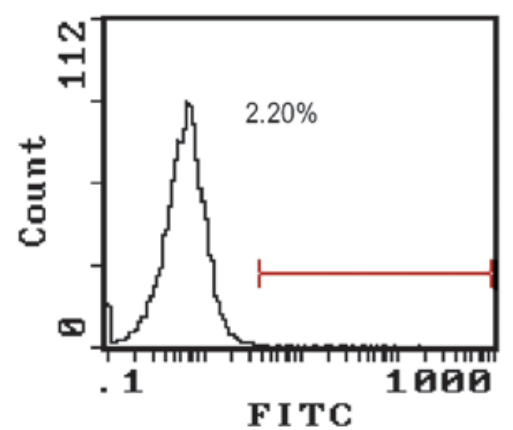

B

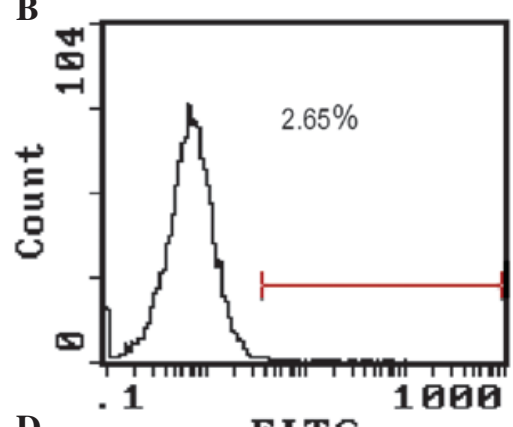

D

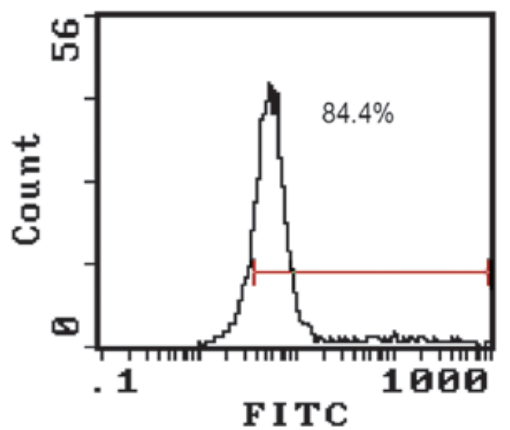

Figure 5. Flow cytometry was used to detect the expression of calreticulin on the surface of MG-63 cells. (A) MG-63 control cells; (B) MG-63 cells without a primary antibody; MG-63 cells treated with (C) cisplatin and (D) capsaicin. FITC, fluorescein.
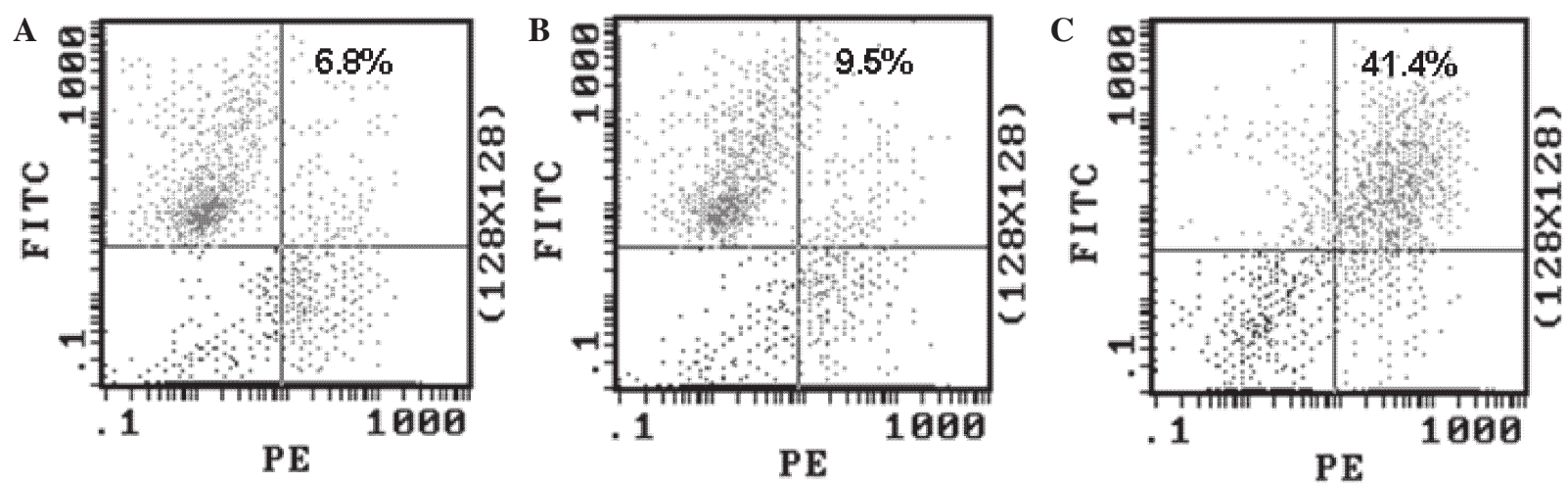

Figure 6. Treatment with capsaicin and calreticulin enhanced the phagocytosis of MG-63 cells by dendritic cells (DCs) in vitro. (A) MG-63 control cells were used as target cells; (B) Cisplatin- and (C) capsaicin-treated MG-63 cells were used as target cells. FITC, fluorescein; PI, propidium iodide.

A

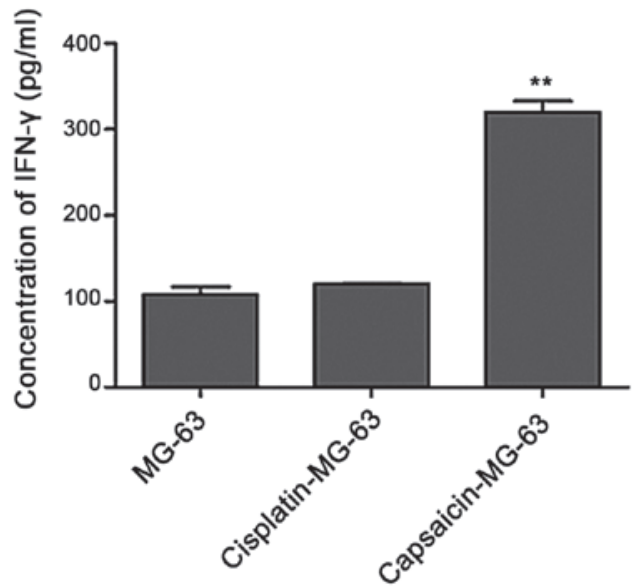

B

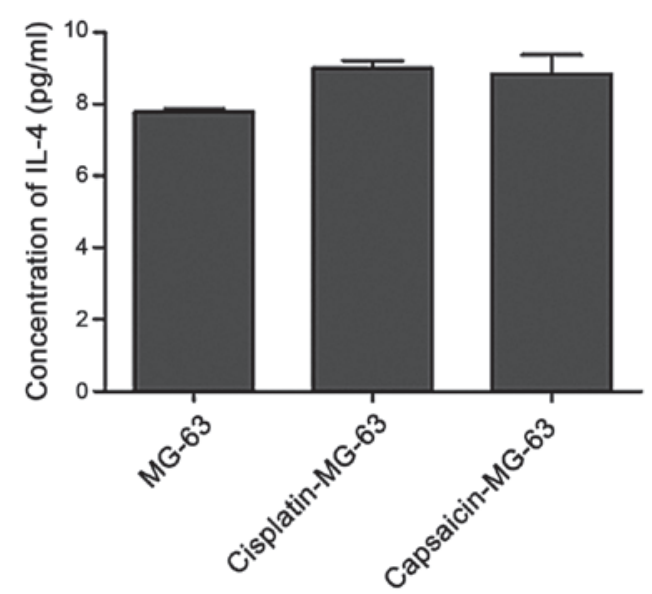

Figure 7. Apoptotic MG-63 cells induced by capsaicin increased the secretion of IFN- $\gamma$ by lyphocytes. ELISA was used to assay the level of (A) IFN- $\gamma$ and (B) interleukin-4. ${ }^{* *} \mathrm{P}<0.01$ vs. MG-63 cells. IFN- $\gamma$, interferon- $\gamma$. 
surface of capsaicin-treated MG-63 cells may be derived from the membrane translocation of CRT from the ER.

DCs serve important roles in processing and presenting of antigens, thus the recognition and phagocytosis of tumour cells by DCs is crucial in ICD (29). In order to evaluate the effect of capsaicin and cisplatin on the phagocytosis of MG-63 cells by DCs, the labeled MG-63 cells treated with capsaicin and cisplatin (the target cells) were co-cultured with the DCs (the effector cells), and FCM analysis was used to determine the phagocytic rate. The results showed that capsaicin-treated MG-63 cells were phagocytosed at a higher rate than MG-63 cells treated with cisplatin, indicating that CRT on the cell surface can enhance the phagocytosis of human OC cells by DCs.

Based on the above results, it can be suggested that capsaicin-treated MG-63 cells can activate lymphocytes through DCs using their phagocytosis and antigen presenting properties. To confirm this conjecture, in the current study MG-63 cells treated with capsaicin were co-cultured with DCs, and these MG-63-loaded DCs were co-cultured with lymphocytes for $24 \mathrm{~h}$. The IFN- $\gamma$ concentration in the supernatant was then analyzed by ELISA. The result showed that, compared with cisplatin-treated MG-63 cells, the capsaicin-treated MG-63 cells induced a higher production and release of IFN- $\gamma$ from lymphocytes into the culture medium.

In conclusion, the results from the present study demonstrate that capsaicin can induce the translocation of a large quantity of CRT from intracellular compartments to the cell surface in human OS cells. In addition, CRT on the human OS cell surface can be used as specific signaling molecules to promote the phagocytosis of tumor cells, thereby mediating tumor cell immunogenic death. This may be one of the underlying molecular mechanisms of capsaicin's anti-tumor cytotoxicity. These results indicate that capsaicin can be explored as a novel drug to treat OS.

\section{Acknowledgements}

The present study was supported by the National Natural Science Foundation of China (grant no. 81402557).

\section{References}

1. Messerschmitt PJ, Garcia RM, Abdul-Karim FW, Greenfield EM and Getty PJ: Osteosarcoma. J Am Acad Orthop Surg 17: 515-527, 2009.

2. Anderson ME: Update on Survival in Osteosarcoma. Orthop Clin North Am 47: 283-292, 2016.

3. Chou AJ, Geller DS and Gorlick R: Therapy for osteosarcoma: Where do we go from here? Paediatr Drugs 10: 315-327, 2008.

4. Siclari VA and Qin L: Targeting the osteosarcoma cancer stem cell. J Orthop Surg Res 5: 78, 2010.

5. Kuijjer ML, Hogendoorn PC and Cleton-Jansen AM: Genome-wide analyses on high-grade osteosarcoma: Making sense of a genomically most unstable tumor. Int J Cancer 133: 2512-2521, 2013.

6. Anninga JK, Gelderblom H, Fiocco M, Kroep JR, Taminiau AH, Hogendoorn PC and Egeler RM: Chemotherapeutic adjuvant treatment for osteosarcoma: Where do we stand? Eur J Cancer 47: 2431-2445, 2011.

7. Kroemer G, Galluzzi L, Kepp O and Zitvogel L: Immunogenic cell death in cancer therapy. Annu Rev Immunol 31: 51-72, 2013.
8. Krysko DV, Garg AD, Kaczmarek A, Krysko O, Agostinis P and Vandenabeele P: Immunogenic cell death and DAMPs in cancer therapy. Nat Rev Cancer 12: 860-875, 2012.

9. Casares N, Pequignot MO, Tesniere A, Ghiringhelli F, Roux S, Chaput N, Schmitt E, Hamai A, Hervas-Stubbs S, Obeid M, et al: Caspase-dependent immunogenicity of doxorubicin-induced tumor cell death. J Exp Med 202: 1691-1701, 2005.

10. Obeid M, Tesniere A, Ghiringhelli F, Fimia GM, Apetoh L, Perfettini JL, Castedo M, Mignot G, Panaretakis T, Casares $\mathrm{N}$, et al: Calreticulin exposure dictates the immunogenicity of cancer cell death. Nat Med 13: 54-61, 2007.

11. Pol J, Vacchelli E, Aranda F, Castoldi F, Eggermont A, Cremer I, Sautès-Fridman C, Fucikova J, Galon J, Spisek R, et al: Trial Watch: Immunogenic cell death inducers for anticancer chemotherapy. Oncoimmunology 4: e1008866, 2015.

12. Beltran J, Ghosh AK and Basu S: Immunotherapy of tumors with neuroimmune ligand capsaicin. J Immunol 178: 3260-3264, 2007.

13. D'Eliseo D, Manzi L and Velotti F: Capsaicin as an inducer of damage-associated molecular patterns (DAMPs) of immunogenic cell death (ICD) in human bladder cancer cells. Cell Stress Chaperones 18: 801-808, 2013.

14. Savill $\mathrm{J}$ and Fadok V: Corpse clearance defines the meaning of cell death. Nature 407: 784-788, 2000.

15. Matzinger P: The danger model: A renewed sense of self. Science 296: 301-305, 2002.

16. Kroemer G, Galluzzi L, Vandenabeele P, Abrams J, Alnemri S, Baehrecke EH, Blagosklonny MV, El-Deiry WS, Golstein P, Green DR, et al; Nomenclature Committee on Cell Death 2009: Classification of cell death: Recommendations of the Nomenclature Committee on Cell Death 2009. Cell Death Differ 16: 3-11, 2009.

17. Zou W: Regulatory T cells, tumour immunity and immunotherapy. Nat Rev Immunol 6: 295-307, 2006.

18. Zitvogel L, Apetoh L, Ghiringhelli F, André F, Tesniere A and Kroemer G: The anticancer immune response: Indispensable for therapeutic success? J Clin Invest 118: 1991-2001, 2008.

19. Han HS, Shim YK, Kim JE, Jeon HJ, Lim SN, Oh TK, Lee KH and Kim ST: A pilot study of adrenal suppression after dexamethasone therapy as an antiemetic in cancer patients. Support Care Cancer 20: 1565-1572, 2012.

20. Garg AD and Agostinis P: Editorial: Immunogenic Cell Death in Cancer: From Benchside Research to Bedside Reality. Front Immunol 7: 110, 2016.

21. Song KH, Jung SY, Kang SM, Kim MH, Ahn J, Hwang SG, Lee JH, Lim DS, Nam SY and Song JY: Induction of immunogenic cell death by radiation-upregulated karyopherin alpha 2 in vitro. Eur J Cell Biol: Apr 11, 2016 (Epub ahead of print).

22. Fučíková J, Bartůňková J and Špíšek R: The Concept of Immunogenic Cell Death in Antitumor Immunity. Klin Onkol 4: 4S48-4S55, 2015 (In Czech).

23. Krause KH and Michalak M: Calreticulin. Cell 88: 439-443, 1997.

24. Johnson S, Michalak M, Opas M and Eggleton P: The ins and outs of calreticulin: From the ER lumen to the extracellular space. Trends Cell Biol 11: 122-129, 2001.

25. Bedard K, Szabo E, Michalak M and Opas M: Cellular functions of endoplasmic reticulum chaperones calreticulin, calnexin, and ERp57. Int Rev Cytol 245: 91-121, 2005.

26. Gold LI, Eggleton P, Sweetwyne MT, Van Duyn LB, Greives MR, Naylor SM, Michalak M and Murphy-Ullrich JE: Calreticulin: Non-endoplasmic reticulum functions in physiology and disease. FASEB J 24: 665-683, 2010.

27. Wu H, Han Y, Qin Y, Cao C, Xia Y, Liu C and Wang Y: Whole-cell vaccine coated with recombinant calreticulin enhances activation of dendritic cells and inducestumour-specific immune responses. Oncol Rep 2: 529-534, 2013.

28. Tesniere A, Panaretakis T, Kepp O, Apetoh L, Ghiringhelli F, Zitvogel L and Kroemer G: Molecular characteristics of immunogenic cancer cell death. Cell Death Differ 1: 3-12, 2008.

29. Son KJ, Choi KR, Lee SJ and Lee H: Immunogenic Cell Death Induced by Ginsenoside Rg3: Significance in Dendritic Cell-based Anti-tumor Immunotherapy. Immune Netw 1: 75-84, 2016.

30. Chao MP, Jaiswal S, Weissman-Tsukamoto R, Alizadeh AA, Gentles AJ, Volkmer J, Weiskopf K, Willingham SB, Raveh T, Park CY, Majeti R and Weissman IL: Calreticulin is the dominant pro-phagocytic signal on multiple human cancers and is counterbalanced by CD47. Sci Transl Med 2: 63ra94, 2010. 